\title{
Prevention of Hypotension following Spinal Anaesthesia for Caesarean Section: Comparison of Pretreatment with Crystalloid and Ephedrine Infusion
}

\author{
Sajil M.S. ${ }^{1}$, Reshma Ulahannan², Sree Sabari S. ${ }^{3}$, Nithin Sathyan ${ }^{4}$ \\ 1, 2, 3,4 Department of Anaesthesiology, Travancore Medical College, Kollam, Kerala, India.
}

\section{ABSTRACT}

\section{BACKGROUND}

Regional anaesthesia has become the preferred technique for caesarean section because of higher incidence of maternal mortality and morbidity associated with general anaesthesia. Spinal hypotension occurs as a result of sympathetic blockade and decreased venous return due to decreased systemic vascular resistance and venous pooling. Such episodes of hypotension have been shown to cause decreased Apgar scores and foetal acidosis. Preloading with intravenous fluids, left uterine displacement and prophylactic/ therapeutic vasopressors have all been used in the prevention and management of hypotension traditionally. However no single method has been proved satisfactory. In terms of neonatal and maternal outcomes, prevention of hypotension is considered superior to treatment of established hypotension. In this study, we compare the efficacy of preloading of crystalloids with Ephedrine infusion in prevention of hypotension following spinal block in caesarean patients.

Objectives- Primary objective is to determine the incidence of hypotension following spinal anaesthesia in patients receiving preloading with crystalloids and preloading with Ephedrine. Secondary objective is to compare intraoperative maternal and foetal adverse effects of pre-treatment with crystalloids and Ephedrine.

\section{METHODS}

An observational study was conducted in 90 patients belonging to ASA I and II categories undergoing elective LSCS. One category received $10 \mathrm{ml} / \mathrm{kg}$ Ringer Lactate and other category $10 \mathrm{mg}$ Ephedrine in $10 \mathrm{ml} / \mathrm{kg}$ Ringer Lactate 15-30 minutes prior to spinal block. All patients received SAB with $22.2 \mathrm{ml} 0.5 \%$ Bupivacaine heavy at L3-L4 space. HR and BP were monitored periodically and fall in MAP of $\geq 20 \%$ was noted and managed with rescue Ephedrine. Maternal adverse events, foetal APGAR scores and umbilical blood gas analysis noted.

\section{RESULTS}

Incidence of hypotension was significantly less in Ephedrine category as compared to crystalloid category. Incidence of maternal adverse events as well as foetal parameters was not significantly different.

\section{CONCLUSIONS}

Preloading with Ephedrine decreases the incidence of maternal hypotension when compared to crystalloids alone.

\section{KEY WORDS}

Caesarean Section, Crystalloids; Ephedrine, Foetal Acidosis, Mean Arterial BP, Preloading, Spinal Hypotension.
Corresponding Author: Dr. Sree Sabari S., Travancore Medical College, Kollam, Kerala, India.

E-mail: drsreesabaris@rediffmail.com

DOI: $10.14260 /$ jemds/2022/50

How to Cite This Article:

Sajil MS, Ulahannan R, Sabari SS, et al. Prevention of hypotension following spinal anaesthesia for caesarean section: comparison of pretreatment with crystalloid and ephedrine infusion. $J$ Evolution Med Dent Sci 2022;11(01):265271, DOI: $10.14260 /$ jemds $/ 2022 / 50$

Submission 12-12-2021,

Peer Review 18-12-2021

Acceptance 29-01-2022,

Published 31-01-2022.

Copyright (c) 2022 Sajil M.S. et al. This is an open access article distributed under Creative Commons Attribution License [Attribution 4.0 International (CC BY 4.0)] 


\section{BACKGROUND}

August Bier introduced spinal anaesthesia into medical practice in 1898..$^{1,2}$ Since its introduction it has been widely used as the anaesthetic method of choice in lower limb and lower abdominal surgeries. Lower segment caesarean sections are the most commonly done surgeries in obstetric practice and spinal anaesthesia is the choice of anaesthesia in nonemergent caesarean deliveries. 3,4 There are evidence of higher risk of foetal acidosis with GA as compared to regional techniques including spinal and epidural.5,6 Superiority of spinal anaesthesia over general anaesthesia in pregnant women is due to faster action, technical simplicity, cost effectiveness and less adverse events. ${ }^{7}$ In addition, spinal anaesthesia avoids airway manipulation, aspiration of gastric contents and effects of general anaesthetic medications on foetus ${ }^{8}$ but spinal anaesthesia is not without adverse effects, the most common being hypotension.

Hypotension following spinal anaesthesia is especially problematic in parturients and is of profound importance as a major adverse event. ${ }^{9}$ The incidence of hypotension following $\mathrm{SAB}$ in pregnant women is roughly estimated to be between 55-90\%.10 Hypotension results from comparatively faster onset of sympatholysis due to increased sensitivity to local anaesthetics during pregnancy and aggravated by aortocaval compression in supine position ${ }^{10-12}$ Prolonged maternal hypotension has been proved to cause foetal bradycardia and acidemia.8 Hypotension can be prevented by various methods including pharmacological and non-pharmacological methods. This is directed at reversing the physiological processes behind hypotension.

Prevention of maternal hypotension, rather than managing it has gained importance over the past few decades. The severity depends on the height of the block, the position, the volume status and indication (elective or emergency) caesarean section. Pharmacological methods include crystalloid or colloid preloading or co-loading along with the use of vasopressors including Ephedrine, Phenylephrine and Mephentermine. Non pharmacological methods including the use of TED stockings, leg wrapping, inflatable boots etc. some studies also depict that delaying supine position after spinal anaesthesia may decrease incidence of hypotension. ${ }^{13}$ No single method has been found successful in preventing spinal hypotension in parturients till date. ${ }^{14}$

The term preloading involves administering $0.5-2 \mathrm{~L}$ of crystalloids, 1530 minutes before initiation of a spinal block. The effect of preloading in general is the filling of capacitance vessels which in turn limits the occurrence of hypotension when venodilation occurs. ${ }^{15}$ Preloading was considered the best way for preventing spinal hypotension for many years. Preloading was particularly important in view of possible fluid depletion due to prolonged fasting periods before elective procedures. Crystalloid preloading versus colloid preloading is an extensively studied topic. Colloid preloading was proved to be better than crystalloid preloading, ${ }^{16}$ but not used in view of cost effectiveness and risk of anaphylactic reactions. ${ }^{17}$ Even though crystalloid preloading is still practised, large volume and rapid prehydration could lead to maternal fluid overload, pulmonary oedema, finally causing hypooxygention in fetus. ${ }^{18}$ The concepts of preloading versus co-loading are extensively being studied now.
Another method in prevention of hypotension is by use of vasopressors. Historically, Ephedrine was considered as the vasopressor of choice to manage hypotension following neuraxial anaesthesia in pregnancy. ${ }^{19}$ This is mainly attributed to the superior effects of Ephedrine in maintaining the uteroplacental blood flow even in presence of hypotension. Uteroplacental sparing action of Ephedrine has been explained by its partial agonism of Beta receptors. Although Ephedrine has been shown to be associated with foetal acidosis, the dosage associated with the same has not been proven. Significance of this acidosis in neonatal outcome is another field where much consensus is yet to be obtained.

Currently Phenylephrine has taken over as the vasopressor of choice (Miller's Anaesthesia 9th Edition) due to less risk of transfer to the foetus and subsequent foetal acidosis. The use of Phenylephrine has also been found associated with decreased intraoperative nausea and vomiting (IONV). ${ }^{20,21}$ This may be due to faster onset of action of phenylephrine. ${ }^{22}$

Phenylephrine causes maternal bradycardia and thereby decrease in cardiac output. Phenylephrine and Ephedrine has been compared based on their respective maternal and foetal outcomes. Another vasopressor being studied is Norepinephrine. When compared to Phenylephrine, Norepinephrine had similar efficacy in maintaining arterial BP.

Prevention of hypotension following spinal anaesthesia in pregnant women has been one of the most widely studied areas in anaesthesia so far. But, a single most effective method is not yet available. Prophylactic vasopressor infusions are now being considered in this regard. The most recent and widely accepted method is a combination of vasopressors including Ephedrine and Phenylephrine along with judicious use of IV fluids tailored for the benefit of individual patient.

This study is an attempt to compare the prophylactic use of crystalloids and Ephedrine bolus in preventing hypotension following SAB. In addition, it also compares the foetal outcome to see if low dose Ephedrine bolus result in significant foetal acidosis.

\section{Objectives}

1. To compare the effect of crystalloid preloading and Ephedrine preloading in maternal hemodynamics for patients undergoing caesarean section under regional anaesthesia.

2. To determine the incidence of hypotension following spinal anaesthesia in patients receiving preloading with crystalloids.

3. To determine the incidence of hypotension following spinal anaesthesia in patients receiving preloading with Ephedrine.

4. To compare intraoperative maternal and foetal adverse effects of pretreatment with crystalloids and Ephedrine.

\section{METHODS}

This is an Observational study conducted in the Department of Anaesthesiology, TMC, Kollam, among Patients admitted for elective LSCS under spinal anaesthesia during the time 
period between March 2020 to March 2021, after approval from institutional ethics committee and an informed written consent from the participants.

\section{Sample Size}

According to Kalpana Rajendra Kulkarni, Amrutha Girish Naik, Sunetra Girish Deshpande et al study, considering the incidence of episodes of hypotension in preloading with crystalloids as $58 \%$ and incidence of episodes of hypotension in preloading with Ephedrine as $28 \%$ at $95 \%$ confidence interval with $80 \%$ power, the sample size is calculated as $\mathrm{N}=(\mathrm{Z} 1-\alpha / 2+\mathrm{Z} 1-\beta) 2 * 2 * \mathrm{p} *(1-\mathrm{p}) /(\mathrm{p} 1-\mathrm{p} 2)^{2}$

Z1- $\alpha / 2$ - two tailed probability for $95 \%$ confidence interval $=$ $1.96 \mathrm{Z} 1-\beta$ - two tailed probability for $80 \%$ power $=0.84 \mathrm{p} 1$ (\%) - incidence of episodes of hypotension in preloading with crystalloids $=0.58$

p2 (\%) - incidence of episodes of hypotension in preloading with Ephedrine =

$0.28 \mathrm{p}$-average incidence of episodes of hypotension in preloading with crystalloids \& incidence of episodes of hypotension in preloading with Ephedrine $=0.43$

$\mathrm{N}=(1.96+0.84)^{\wedge} 2 * 2 * 0.43 *(1-0.43)^{\wedge} 2 /(0.58-0.28)^{\wedge} 2$ $\mathrm{N}=42.75$

Thus, the sample size required for each group is 45 and the total sample size is 90 .

\section{Inclusion Criteria}

- Women posted for elective LSCS with singleton pregnancy of 37-41 weeks of gestation

- $\quad$ Age between 20-35 yrs

- Weight between 45-80 kg

- Height between $145-165 \mathrm{~cm}$

- Women belonging to ASA I and II category

\section{Exclusion Criteria}

- Parturients with obstetric complications like pregnancy induced hypertension, obesity, pre-existing hypertension

- $\quad$ Patients who develop labor pains before surgery

- Patients with contraindications for spinal anaesthesia

90 patients belonging to age group 2035 yrs, weighing 45-80 kg, belonging to ASA I and II category, undergoing elective LSCS was included in the study. First patient will receive crystalloid pretreatment, second one will receive Ephedrine preloading and so on. All the patients receiving crystalloid pretreatment was named as category 1 and the ones receiving Ephedrine preloading was category 2.

A proper pre anaesthetic check-up was carried out preferably on the day before the procedure. All patients was advised fasting for a period of minimum $8 \mathrm{hrs}$ prior to surgery and was pre-medicated with Tab. Pantoprazole $40 \mathrm{mg}$ $\mathrm{PO}$, the night before and $2 \mathrm{hrs}$ prior to surgery. On arrival to $\mathrm{OR}$, a baseline heart rate (HR), systolic blood pressure (SBP) and diastolic blood pressure (DBP) was noted. Intravenous access was secured with18G cannula. Half of the patients will then receive $10 \mathrm{ml} / \mathrm{kg}$ of Ringer Lactate over a period of $15-$
30 minutes whereas the other half will receive $10 \mathrm{mg}$ of Ephedrine as infusion in $10 \mathrm{ml} / \mathrm{kg}$ Ringer Lactate, both of which was initiated 15-30 minutes before spinal block. All the patients will receive $5 \mathrm{ml} / \mathrm{kg} / \mathrm{hr}$ of crystalloids thereafter till the end of procedure.

Spinal block was performed in left lateral position with 25G Quincke needle in L3-L4 space. On free flow of CSF, 2- 2.2 $\mathrm{ml}$ of $0.5 \%$ hyperbaric Bupivacaine was administered to all patients. Following this, all patients was positioned supine with a left tilt and waited till acquiring adequate sensory block. After spinal block, HR and BP was monitored every 2 minutes till delivery of the baby and thereafter every 5 minutes till the end of procedure and MAP was calculated. A fall in MAP of $>20 \%$ of the baseline value was taken as hypotensive episode. Such episodes was treated with crystalloids and rescue doses of $6 \mathrm{mg}$ IV Ephedrine as required. Number of such episodes was recorded. Further, occurrence of nausea, vomiting, reactive hypertension was noted.

After delivery of the baby, all mothers will receive 20IU of IV Oxytocin. Umbilical cord blood was sampled for gas analysis and APGAR scores was recorded at 1 minute and 5 minutes by the attending Pediatrician.

\section{Statistical Methods}

The collected data were entered in Microsoft Excel data sheet and Statistical Package for the Social Science (SPSS; ver.20.0) was used for statistical analysis. Continuous data was represented as mean and standard deviation whereas categorical variables are present as numbers and percentages. Student's t-test was used as the test of significance to identify the mean difference between two categories. The $\mathrm{p}$-value $<0.05$ was considered as statistically significant. Observations were recorded both graphically and numerically.

\section{RESULTS}

This observational study was conducted in Travancore Medical College, Kollam, Kerala after acquiring institutional ethical clearance. Study was conducted over a period of one year involving a total of 90 parturients. All of them belonged to ASA I or II category, posted for elective LSCS under spinal anaesthesia. Category 1 consisting of 45 patients received crystalloids as pretreatment and Category 2 of 45 patients received Ephedrine as pretreatment.

\section{Demographic Data}

All 90 patients were 20-35 years of age. Most patients belonged to $25-30$ yrs (43 patients) and 30-35 yrs category had the least number (17 patients). The age distribution in category 1 and 2 were comparable. The mean age in category 1 was $27.02 \pm 3.487$ whereas in category 2 it was $26.84 \pm$ 3.529. The mean height in category 1 was $155.11 \pm 4.007$ and that in category 2 was $155.36 \pm 4.931$. Similarly the mean weight in both categories was also comparable. 


\section{Mean MAP}

As observed from the data there is fall in MAP in both categories after $\mathrm{SAB}$, but the fall is greater in category 1 than category 2 . Also, MAP was significantly lower in category $1 \mathrm{cp}$ value $<0.05$ ) than category 2 , during 3-9 minutes following spinal block.
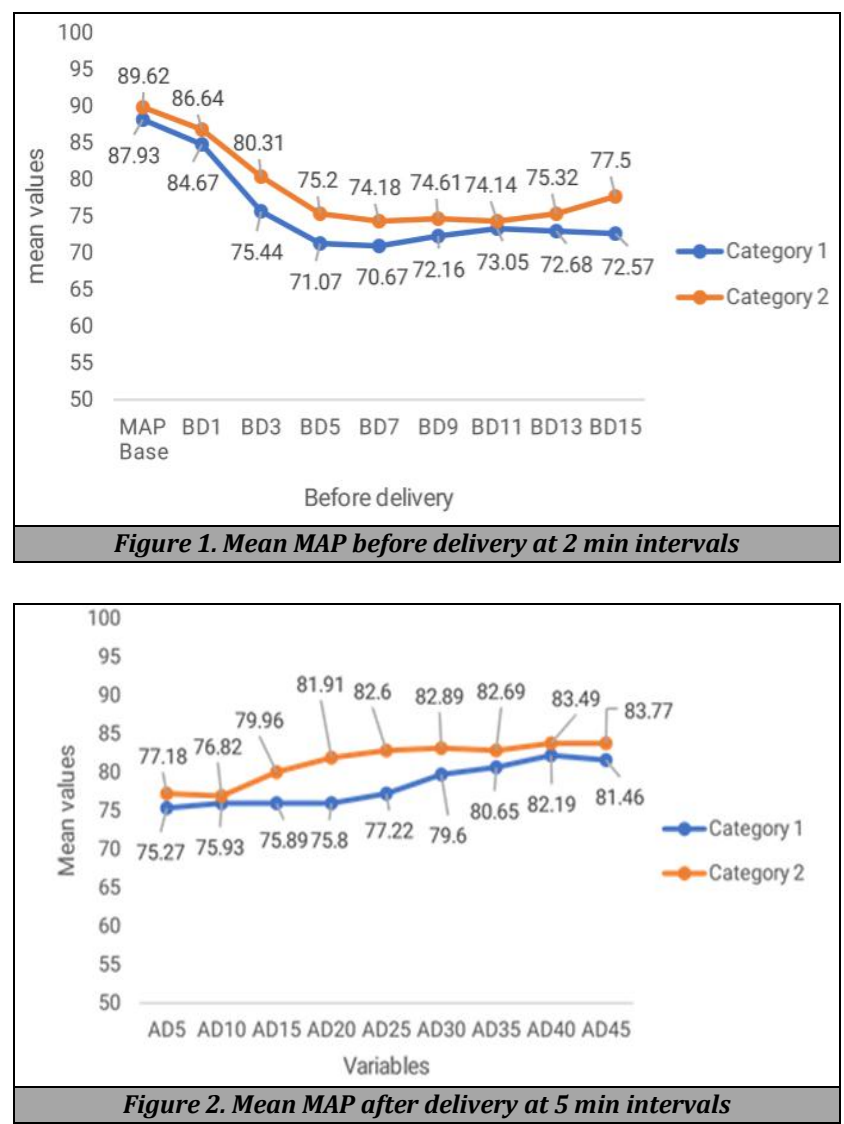

\section{Fetal Parameters}

Fetal parameters including APGAR scores, umbilical blood $\mathrm{pH}$ were compared in two categories. The APGAR score at $1 \mathrm{~min}$ and $5 \mathrm{~min}$ were good in both the categories. There were no statistically significant differences between two categories.

\section{Umbilical Blood Gas Analysis}

The blood bas analysis data in both categories of the study. Mean blood pH was $7.2438 \pm 0.06383$ in crystalloid category and $7.2378 \pm 0.06299$ in Ephedrine category. The $p$ value was 0.655 which was not considered statistically significant. Similarly, the pO2 and pCO2 values compared also revealed no statistical significance in two categories.

\begin{tabular}{|c|c|c|c|c|c|c|}
\hline Variable & Category & $\mathbf{N}$ & Mean & SD & $\begin{array}{l}\text { Independent } \\
\text { sample } t \text { test }\end{array}$ & p value \\
\hline \multirow{2}{*}{ p02 } & Category 1 & 45 & 22.56 & 4.892 & \multirow{2}{*}{1.495} & \multirow{2}{*}{0.138} \\
\hline & Category 2 & 45 & 24.36 & 6.425 & & \\
\hline \multicolumn{7}{|c|}{ Table 1. Umbilical blood p02 } \\
\hline
\end{tabular}

\begin{tabular}{|ccc|cc|cc|}
\hline Variable & Category & N & Mean & SD & $\begin{array}{c}\text { Independent } \\
\text { sample t test }\end{array}$ & p value \\
& Category 1 & 45 & 42.93 & 5.319 & 1.528 & 0.130 \\
\hline & Category 2 & 45 & 41.27 & 5.024 & 1.528 & \\
\hline \multicolumn{7}{|c|}{ Figure 2. Comparison of pO2 } \\
\hline
\end{tabular}

\section{Maternal Adverse Events}

Nausea / vomiting and reactive hypertension were studied as the possible maternal adverse outcomes. Incidence of nausea or vomiting was less in both categories and was comparable with no statistical significance. Reactive hypertension was not actually observed in any category.

\begin{tabular}{|cccccc|}
\hline N/V & \multicolumn{2}{c}{ Category } & Total & $\begin{array}{c}\text { Chi square } \\
\text { value }\end{array}$ & p value \\
Yes & $7(15.6 \%)$ & $5(11.1 \%)$ & $12(13.3 \%)$ & & \\
No & $38(84.4 \%)$ & $40(88.9 \%)$ & $78(86.7 \%)$ & 0.385 & 0.535 \\
Total & $45(100 \%)$ & $45(100 \%)$ & $90(100 \%)$ & \\
\hline \multicolumn{5}{|c|}{ Table 3. Nausea / vomiting in two categories } \\
\hline $\begin{array}{l}\text { p value was calculated by chi square test, p }<0.05 \text { considered as statistically } \\
\text { significant }\end{array}$ \\
\hline \multicolumn{7}{|c|}{} \\
\hline
\end{tabular}

\section{Incidence of Hypotension}

The overall incidence of hypotension in crystalloid category was higher than Ephedrine category. A total of 43 patients developed hypotension out of the 90 patients studied. With 45 patients in each category, 28 patients in category I and 15 patients in category II had significant hypotension requiring rescue Ephedrine. Incidence of hypotension was $62.2 \%$ in category I and $33.3 \%$ in category II with a p value of 0.006 which is highly significant.

\begin{tabular}{|c|c|c|c|c|c|}
\hline \multirow{2}{*}{ Hypotension } & \multicolumn{2}{|c|}{ Category } & \multirow{2}{*}{ Total } & \multirow{2}{*}{$\begin{array}{c}\text { Chi square } \\
\text { value }\end{array}$} & \multirow{2}{*}{$p$ value } \\
\hline & Category 1 & Category 2 & & & \\
\hline Yes & $28(62.2 \%)$ & $15(33.3 \%)$ & $43(47.8 \%)$ & \multirow{3}{*}{7.526} & \multirow{3}{*}{0.006} \\
\hline No & $17(37.8 \%)$ & $30(66.7 \%)$ & $47(52.2 \%)$ & & \\
\hline Total & $45(100 \%)$ & $45(100 \%)$ & $90(100 \%)$ & & \\
\hline \multicolumn{6}{|c|}{ Table 4. Incidence of hypotension in each category } \\
\hline
\end{tabular}

\section{DISCUSSION}

Caesarean sections have emerged to be the most common surgery in obstetric practice. In practice almost $90 \%$ of these patients undergo LSCS under spinal anaesthesia. Hypotension following spinal anaesthesia, even though a well-marked complication is not $100 \%$ preventable.

Anaesthesiologists around the world have not yet reached at an equivocal prevention for this problem. Even though there are a variety of practices to prevent spinal hypotension, a single effective solution is not established till date. Preloading with crystalloids is widely practiced over the years and has not lost its significance, especially in peripheral centres.

A combination of pharmacological as well as nonpharmacological preventive methods adjusted for each patient's unique features might help in successfully preventing or combating hypotension following spinal anaesthesia. ${ }^{23}$

Fluid preloading with crystalloids for Caesarean section under regional anaesthesia has been practiced as routine and considered to be a safe and effective method of reducing the incidence of hypotension especially in developing countries. Many regimens have been recommended, including preload volumes of up to 3-4 litres. Even though recent studies suggest co-loading to be more advantageous, preloading is still widely practiced. ${ }^{24}$ These are time consuming and may prove to be dangerous to the pregnant mother due to risk of 
circulatory overload, and also by causing significant hemodilution and over distension of the bladder. ${ }^{25-27}$

Similarly, Ephedrine was considered as the sympathomimetic of choice for spinal hypotension in pregnancy for ages. The ability of Ephedrine to maintain an unaltered uteroplacental flow is thought to be reason behind this. In recent times, Ephedrine is increasingly replaced by phenylephrine boluses as well as infusion claiming that risk of foetal acidosis is more with Ephedrine. ${ }^{28}$ Ephedrine also has weak prophylactic ability. Studies comparing various dose regimens for phenylephrine has also been well established. Most of the studies comparing Ephedrine and phenylephrine has come to conclude that both are equally effective in preventing spinal hypotension. $29,30,31$

This observational study conducted in our institution compared effects of preloading with crystalloids and low dose Ephedrine infusion on prevention of hypotension following spinal anaesthesia in patients undergoing elective LSCS. Primary objective was to compare the incidence of hypotension and the secondary objective was to look at the foetal and maternal complications in individual groups. Of a total 90 patient studied, 45 patients were preloaded with $10 \mathrm{ml} / \mathrm{kg}$ of Ringer Lactate and others with $10 \mathrm{mg}$ Ephedrine in $10 \mathrm{ml} / \mathrm{kg}$ of Ringer Lactate 15-30 minutes prior to sub arachnoid block.

Morphological characteristics and demography were comparable in both groups namely age, height and weight. There was no statistically significant difference in between the groups. Baseline vital signs including HR, SBP, DBP and MAP was calculated. For research purpose, mean arterial BP is considered in our study as it was thought to be more reliable.

The primary objective was to compare the incidence of hypotension in each group. We found that the incidence of hypotension in Category 1 (crystalloid group) was $62.2 \%$ whereas in Category 2 (Ephedrine group), it was 33-3\%. A p value of $<0.05$ proved statistical significance. The number of patients who developed hypotension in each group is well depicted in Table 4 . These results were comparable with those obtained in a study by Kalpana Rajendra et al.

The difference in our study as compared to the abovementioned study is that we have considered MAP as the basis when they have considered SBP. They considered a fall in $\mathrm{SBP} \geq 20 \%$ as criteria for hypotension.

On considering MAP in our study, the fall in BP was most evident at 3-9 minutes following SAB which was evident from the statistically significant $p$ valves at these respective time intervals. This fall could explain the fast onset sympatholysis following SAB along with the assumed supine position after block. Also, fall in BP was also observed in the time following delivery of the baby, which was also found to be significant. This fall could possibly be also attributed to rapid infusion of oxytocin following delivery of foetus.

Secondary objectives were to compare foetal and maternal complications in respective groups. Maternal adverse events were compared on basis of occurrence of nausea, vomiting and reactive hypertension. While none of the 90 patients developed a reactive hypertension ( $\geq 20 \%$ increase from baseline MAP), incidence of nausea/vomiting was comparable in both groups. Incidence was $15.6 \%$ in Category 1 and $11.1 \%$ in Category 2 which was found to be statistically not significant.
Foetal parameters compared included APGAR scores at 1 min and 5 minutes along with umbilical cord blood gas analysis. The mean APGAR score at 1 minute was 8.47 in category 1 and 8.6 in category 2 . At 5 minutes the mean scores were 9.11 and 9.09 in the respective categories. The APGAR scores at 1 minute and 5 minutes were similar with $\mathrm{p}=0.209$ and $\mathrm{p}=0.729$ respectively. These findings were in agreement with similar studies. ${ }^{32}$

Umbilical blood gas analysis compared $\mathrm{pH}, \mathrm{pO} 2$ and $\mathrm{pCO} 2$ between two categories. While comparing $\mathrm{pH}$ in two categories, we observed that the mean $\mathrm{pH}$ in category 1 was 7.23 and that of category 2 was 7.34. Our study did not find any significant foetal acidosis in the category with ephedrine preload. There were no significant differences in mean p02 and pCO2 in two categories. All three parameters were comparable in two groups with no statistical significance in individual categories.

A randomized single blind comparative study done by Bhagat Kumar Hegde et al in 90 patients showed similar results (2017). In this study, patients were randomly allocated into three groups of which one group received crystalloids, second group received Ephedrine and third group received half dose of both. Incidence of hypotension was $43.33 \%, 16.66 \%$ and $3.33 \%$ respectively which was in line with the results of our study. 33

Heba Omar et al published a study in 2016 in which 50 patients were randomly allocated into two groups. ${ }^{34}$ One group was preloaded with $15 \mathrm{ml} / \mathrm{kg} \mathrm{RL}$ and the other received bolus doses of Ephedrine $5 \mathrm{mg}$ after 1 minute, $5 \mathrm{mg}$ after second minute and $1 \mathrm{mg}$ thereafter till 15 minutes after spinal block. Incidence of hypotension was $24 \%$ and $48 \%$ in these respective groups. Incidence of nausea/vomiting was also significantly higher in fluid group. These findings were similar to those obtained in our study also.

Another study conducted in 2017 by Madhu D et al compared crystalloid preloading with Ephedrine infusions in lower abdominal surgeries. Here Ephedrine was administered at the rate of $5 \mathrm{mg} / \mathrm{min}$ for the first two minutes followed by $1 \mathrm{mg} / \mathrm{min}$ for the next 18 minutes following spinal block. Hypotension was found to be $82.2 \%$ in control group as opposed to $22.5 \%$ in Ephedrine group. They also noted incidence of reactive hypertension of $7.2 \%$ in Ephedrine group, which was not present in our study. ${ }^{35}$

A randomized study by Desalu et al (2005) compared preloading with $0.9 \%$ normal saline and $30 \mathrm{mg}$ Ephedrine infusion in 60 subjects. Hypotension incidence was $70 \%$ in group 1 and $40 \%$ in group 2 . Incidence of adverse events was also less in group 2. APGAR scores at 1 minute and 5 minutes were comparable. ${ }^{36}$

Gajraj et al found that the incidence of hypotension was $55 \%$ in the crystalloid group and $22 \%$ in the infusion group. They concluded that a prophylactic Ephedrine infusion is effective for minimizing and managing hypotension associated with spinal anaesthesia and compares favourably with crystalloid administration in terms of efficacy and incidence of side effects. ${ }^{37}$

Bhovi et al. studied the efficacy of Ephedrine for preventing hypotension in patients undergoing caesarean section under spinal anaesthesia. Patients were randomly allocated to receive either Ephedrine infusion $50 \mathrm{mg}$ in 500 $\mathrm{ml}$ of Ringer's Lactate immediately after administration of spinal anaesthesia at a rate of $50 \mathrm{ml} / \mathrm{min}$ for first 2 minutes, 
and $10 \mathrm{ml} / \mathrm{min}$ for next $18 \mathrm{~min}$ or $20 \mathrm{ml} / \mathrm{kg}$ of Ringer's Lactate solution as a preloading solution before the subarachnoid block. The study revealed that the incidence of hypotension was significantly higher in the patient group who received fluid preload $(60 \%)$ compared with $(12 \%)$ in the patients group who received Ephedrine infusion. The incidence of hypotension in the Ephedrine group in this study was $(12 \%)$ in comparison with our study the incidence of hypotension in the Ephedrine group was (24\%), this difference may be due to different doses of Ephedrine used and different volume of infusion.

Loughrey et al conducted a study on 68 patients posted for elective LSCS with different doses of prophylactic Ephedrine boluses rather than infusion. After patients had received an intravenous preload of $0.5 \mathrm{~L}$ of lactated Ringer's solution, patients were randomized to receive a simultaneous $2 \mathrm{~mL}$ bolus intravenously of either $0.9 \%$ saline, Ephedrine 6 $\mathrm{mg}$, or Ephedrine $12 \mathrm{mg}$. There was a significantly higher incidence of hypotension in control group $(60 \%)$ compared to Group E-12 (27\%), but not in Group E-6 (50\%). There were no significant differences in the incidence of maternal nausea or vomiting, or of neonatal acidemia between groups. ${ }^{38}$

Young $\mathrm{Oh}$ et al studied the influence of timing of administration of crystalloid in preventing spinal hypotension. The incidence of hypotension was lower in the co-load group compared to the preload group (53\% vs. $83 \%$ ). The incidence of nausea was also lower in the co-load group. Neonatal outcome measures were comparable between two groups.

In an observational study conducted by Bhattacharya D et al, 80 parturients in the age group of 20 to 40 years, posted for elective caesarean section were selected. After preloading with $500 \mathrm{ml}$ of ringer lactate solution, all the patients received spinal anaesthesia with $2 \mathrm{ml}$ Inj. Bupivacaine $0.5 \%$ (heavy). The infusion of Ephedrine at the rate of $1.25 \mathrm{mg} / \mathrm{min}$ via an infusion pump was started and was continued till clamping of the umbilical cord. The incidence of hypotension was $11 \%$ which was found to be lower when compared with other studies. ${ }^{39}$

Jain et al conducted a study in 60 parturients posted for elective LSCS by comparing crystalloid co-loading and preloading. Incidence of hypotension was $40 \%$ in preload group and $46.66 \%$ in co-load group, which was statistically not significant $(\mathrm{p}=0.602)$.Incidence of nausea and vomiting, vasopressor requirement and neonatal outcome were comparable in both groups. Hence they concluded that coloading with crystalloids is equally effective as preloading to prevent spinal anaesthesia induced maternal hypotension.39These results were different from many similar studies. ${ }^{40}$

Another area where extensive studies were done is crystalloid versus colloid loading to prevent spinal hypotension. Dahlgren et al, did a randomized, doubleblinded study of 110 patients presenting for elective cesarean section with $1 \mathrm{~L}$ lactated Ringer's solution or $1 \mathrm{~L} 3 \%$ dextran 60 solution immediately before spinal anesthesia. Dextran reduced the incidence of clinically significant hypotension from 60 to $30 \%$ compared to Ringer's solution. There were no significant differences in neonatal outcome between treatment groups. ${ }^{9}$

\section{Limitation}

1. Sample size was small considering easily available participants.

2. A fixed dose of drug only used. Different drug doses could have been compared.

3. Mixed umbilical blood was used for blood gas analysis instead of arterial blood.

4. Widely studied topic.

5. Recently practiced coloading is not considered.

\section{CONCLUSIONS}

Post spinal hypotension is a major challenge for Anaesthesiologists wordwide especially in a pregnant patient. This study concludes that preloading with Ephedrine $10 \mathrm{mg}$ is better as compared to preloading with crystalloids (RL) in preventing maternal hypotension following spinal anaesthesia. Also with the used dose of intravenous Ephedrine, there were no significant maternal adverse events or evidence of foetal acidosis. Thus use of prophylactic Ephedrine infusion may be beneficial in low doses.

Data sharing statement provided by the authors is available with the full text of this article at jemds.com.

Financial or other competing interests: None.

Disclosure forms provided by the authors are available with the full text of this article at jemds.com.

\section{REFERENCES}

[1] Mandabach MG. The early history of spinal anesthesia. International Congress Series 2002;1242:163-8.

[2] The history of spinal anesthesia. Available from: http://www.asaabstracts.com/strands/asaabstracts/ab stract.htm? year $=2008$ \&index $=12$ \&absnum $=328$

[3] Traynor AJ, Aragon M, Ghosh D, et al. Obstetric anesthesia workforce survey: a 30-year update. Anesth Analg 2016;122(6):1939-46.

[4] Shibli KU, Russell IF. A survey of anaesthetic techniques used for caesarean section in the UK in 1997. Int J Obstet Anesth 2000;9(3):160-7.

[5] McGlennan A, Mustafa A. General anaesthesia for Caesarean section. Continuing Education in Anaesthesia Critical Care \& Pain 2009;9(5):148-51.

[6] Petropoulos G, Siristatidis C, Salamalekis E, et al. Spinal and epidural versus general anesthesia for elective Cesarean section at term: effect on the acid-base status of the mother and newborn. J Matern Fetal Neonatal Med 2003;13(4):260-6.

[7] Bjørnestad E, Rosseland LA. Anaesthesia for caesarean section. Tidsskr Nor Laegeforen 2010;130(7):748-51.

[8] Šklebar I, Bujas T, Habek D. Spinal anaesthesia-induced hypotension in obstetrics: prevention and therapy. Acta Clin Croat 2019;58(Suppl 1):90 5.

[9] Rout CC, Rocke DA, Levin J, et al. A reevaluation of the role of crystalloid preload in the prevention of hypotension associated with spinal anesthesia for elective cesarean section. Anesthesiology 1993;79(2):262-9. 
[10] Mercier FJ, Bonnet MP, De la Dorie A, et al. Spinal anaesthesia for caesarean section: fluid loading, vasopressors and hypotension. Ann Fr Anesth Reanim 2007;26(7-8):688-93.

[11] Rout C, Rocke DA. Spinal hypotension associated with cesarean section: will preload ever work? Anesthesiology 1999;91:1565-7.

[12] Mitra JK, Roy J, Bhattacharyya P, et al. Changing trends in the management of hypotension following spinal anesthesia in cesarean section. J Postgrad Med 2013;59(2):121-6.

[13] Køhler F, Sørensen JF, Helbo-Hansen HS. Effect of delayed supine positioning after induction of spinal anaesthesia for caesarean section. Acta Anaesthesiol Scand 2002;46(4):441-6.

[14] Chooi C, Cox JJ, Lumb RS, et al. Techniques for preventing hypotension during spinal anaesthesia for caesarean section. Cochrane Database Syst Rev 2017;8(8):CD002251.

[15] Nishikawa K, Yokoyama N, Saito S, et al. Comparison of effects of rapid colloid loading before and after spinal anesthesia on maternal hemodynamics and neonatal outcomes in cesarean section. J Clin Monit Comput 2007;21(2):125-9.

[16] Dahlgren G, Granath F, Pregner K, et al. Colloid vs. crystalloid preloading to prevent maternal hypotension during spinal anesthesia for elective cesarean section. Acta Anaesthesiol Scand 2005;49(8):1200-6.

[17] Rudloff E, Hopper K. Crystalloid and colloid compositions and their impact. Front Vet Sci 2021;8:639848.

[18] Ducros L, Bonnin P, Cholley BP, et al. Increasing maternal blood pressure with ephedrine increases uterine artery blood flow velocity during uterine contraction. Anesthesiology 2002;96(3):612-6.

[19] Shnider SM, de Lorimier AA, Holl JW, et al. Vasopressors in obstetrics. I. Correction of fetal acidosis with ephedrine during spinal hypotension. Am J Obstet Gynecol 1968;102(7):911-9.

[20] Habib AS. A review of the impact of phenylephrine administration on maternal hemodynamics and maternal and neonatal outcomes in women undergoing cesarean delivery under spinal anesthesia. Anesth Analg 2012;114(2):377-90.

[21] Bedson R, Riccoboni A. Physiology of pregnancy: clinical anaesthetic implications. Continuing Education in Anaesthesia Critical Care \& Pain 2014;14(2):69-72.

[22] Datta S, Kodali BS, Segal S. Maternal physiological changes during pregnancy, labor, and the postpartum period. In: Obstetric anesthesia handbook. New York, NY: Springer 2010:1-14.

[23] Indications for and risks of elective cesarean section. Available

from: https://www.ncbi.nlm.nih.gov/pmc/articles/ PMC4555060

[24] Stjernholm YV, Petersson K, Eneroth E. Changed indications for cesarean sections. Acta Obstet Gynecol Scand 2010;89(1):49-53.
[25] Iddrisu M, Khan ZH. Anesthesia for cesarean delivery: general or regional anesthesia-a systematic review. AinShams J Anesthesiol 2021;13(1):1.

[26] Afolabi BB, Lesi FEA. Regional versus general anaesthesia for caesarean section. Cochrane Database Sys Rev 2012;10:CD004350.

[27] Aksoy H, Aksoy U, Yucel B, et al. Blood loss in elective cesarean section: is there a difference related to the type of anesthesia? A randomized prospective study. J Turk Ger Gynecol Assoc 2015;16(3):158-63.

[28] Bhatia M, Banerjee K, Dixit P, et al. Assessment of variation in cesarean delivery rates between public and private health facilities in India From 2005 to 2016. JAMA Network Open 2020;3(8):e2015022.

[29] Griffiths SK, Campbell JP. Placental structure, function and drug transfer. Continuing Education in Anaesthesia Critical Care \& Pain 2015;15(2):84-9.

[30] Açıkel A, Öztürk T, Göker A, et al. Comparison of Patient Satisfaction Between General and Spinal Anaesthesia in Emergency Caesarean Deliveries. Turk J Anaesthesiol Reanim 2017;45(1):41-6.

[31] Olawin AM, M Das J. Spinal Anesthesia. In: StatPearls [Internet]. Treasure Island (FL): StatPearls Publishing 2021. Available from: http://www.ncbi.nlm.nih.gov/books/NBK537299/

[32] Ahmed HO, Hossam M, Adel A. Volume preload versus ephedrine infusion for prevention of hypotension due to spinal anesthesia for cesarean section. Open Journal of Anesthesiology 2016;6(3):37-44.

[33] Greene NM. Uptake and elimination of local anesthetics during spinal anesthesia. Anesth Analg 1983;62(11):1013-24.

[34] Salinas FV, Sueda LA, Liu SS. Physiology of spinal anaesthesia and practical suggestions for successful spinal anaesthesia. Best Pract Res Clin Anaesthesiol 2003;17(3):289-303.

[35] Sakura S. Factors influencing the level of spinal anesthesia: (II). Patient characteristics and technique of injection. Masui 2000;49(2):150-8.

[36] Huang YY, Chang KY. Sensory block level prediction of spinal anaesthesia with $0.5 \%$ hyperbaric bupivacaine: a retrospective study. Sci Rep 2021;11(1):9105.

[37] Reynolds F, Seed PT. Anaesthesia for caesarean section and neonatal acid-base status: a meta-analysis. Anaesthesia 2005;60(7):636-53.

[38] Sharwood-Smith G, Drummond GB. Hypotension in obstetric spinal anaesthesia: a lesson from preeclampsia. Br J Anaesth 2009;102(3):291-4.

[39] Dyer RA, Reed AR, van Dyk D, et al. Hemodynamic effects of ephedrine, phenylephrine, and the coadministration of phenylephrine with oxytocin during spinal anesthesia for elective cesarean delivery. Anesthesiology 2009;111(4):753-65.

[40] Aya AGM, Mangin R, Vialles N, et al. Patients with severe preeclampsia experience less hypotension during spinal anesthesia for elective cesarean delivery than healthy parturients: aprospective cohort comparison. Anesth Analg 2003;97(3):867-72. 